\title{
Comparison of three ${ }^{18}$ F-labeled carboxylic acids with ${ }^{18} \mathrm{~F}-\mathrm{FDG}$ of the differentiation tumor from inflammation in model mice
}

Hongliang Wang ${ }^{12^{*}}$, Ganghua Tang ${ }^{2^{*}}$, Kongzhen $\mathrm{Hu}^{2}$, Tingting Huang ${ }^{2}$, Xiang Liang ${ }^{2}$, Zhifang Wu ${ }^{1}$ and Sijin $\mathrm{Li}^{1}$

\begin{abstract}
Background: The aim of this study was to compare the properties and feasibility of the glucose analog, 2- ${ }^{18} \mathrm{~F}$-fluoro-2-deoxy-D-glucose $\left({ }^{18} \mathrm{~F}-\mathrm{FDG}\right)$, three short ${ }^{18} \mathrm{~F}$-labeled carboxylic acids, ${ }^{18} \mathrm{~F}$-fluoroacetate $\left({ }^{18} \mathrm{~F}-\mathrm{FAC}\right)$, $2-{ }^{18} \mathrm{~F}$-fluoropropionic acid $\left({ }^{18} \mathrm{~F}-\mathrm{FPA}\right)$ and $4-\left({ }^{18} \mathrm{~F}\right)$ fluorobenzoic acid $\left({ }^{18} \mathrm{~F}-\mathrm{FBA}\right)$, for differentiating tumors from inflammation.

Methods: Biodistributions of ${ }^{18} \mathrm{~F}-\mathrm{FAC},{ }^{18} \mathrm{~F}$-FPA and ${ }^{18} \mathrm{~F}$-FBA were determined on normal Kunming mice, and positron emission tomography (PET) imaging with these tracers were performed on the separate tumor-bearing mice model and inflammation mice model in comparison with ${ }^{18} \mathrm{~F}-\mathrm{FDG}$.

Results: Biodistribution results showed that ${ }^{18} \mathrm{~F}-\mathrm{FAC}$ and ${ }^{18} \mathrm{~F}$-FPA had similar biodistribution profiles and the slow radioactivity clearance from most tissues excluding the in vivo defluorination of ${ }^{18} \mathrm{~F}-\mathrm{FAC}$, and ${ }^{18} \mathrm{~F}-\mathrm{FBA}$ demonstrated a lower uptake and fast clearance in most tissues. PET imaging with ${ }^{18} \mathrm{~F}-\mathrm{FDG},{ }^{18} \mathrm{~F}-\mathrm{FAC}$ and ${ }^{18} \mathrm{~F}$-FPA revealed the high uptake in both tumor and inflammatory lesions. The ratios of tumor-to-inflammation were $1.63 \pm 0.28$ for ${ }^{18} \mathrm{~F}-\mathrm{FDG}, 1.20 \pm 0.38$ for ${ }^{18} \mathrm{~F}-\mathrm{FAC}$, and $1.41 \pm 0.33$ for ${ }^{18} \mathrm{~F}-\mathrm{FPA}$ at 60 min postinjection, respectively. While clear tumor images with high contrast between tumor and inflammation lesion were observed in ${ }^{18} \mathrm{~F}$-FBA/PET with the highest ratio of tumor-to-inflammation (1.98 \pm 0.15$)$.
\end{abstract}

Conclusions: Our data demonstrated ${ }^{18} \mathrm{~F}-\mathrm{FBA}$ is a promising PET probe to distinguish tumor from inflammation. But the further modification of ${ }^{18} \mathrm{~F}$-FBA structure is required to improve its pharmacokinetics.

Keywords: ${ }^{18}$ F-fluoroacetate, $2-{ }^{18}$-fluoropropionic acid, $4-{ }^{18}$-fluorobenzoic acid, Biodistribution, PET imaging

\section{Background}

Positron emission tomography (PET) has been used for assessing neoplasms for several decades. $2{ }^{18} \mathrm{~F}$-fluoro-2deoxy-D-glucose $\left({ }^{18} \mathrm{~F}\right.$-FDG) is the most widely used PET probe to detect cancer based on elevated glucose metabolism in the malignant tissue (Warburg effect), as a result of increased expression of cellular membrane glucose transporters (mainly transporter 1 ) and enhanced hexokinase II enzymatic activity in tumor cells $[1,2]$. There are some limitations of ${ }^{18} \mathrm{~F}$-FDG in tumor imaging, such as the uptake in activated inflammatory cells causing the falsepositive results $[3,4]$, the low specificity for justified

* Correspondence: hongliang0812@163.com; gtang0224@126.com ${ }^{1}$ Department of Nuclear Medicine, First Hospital of Shanxi Medical University, Taiyuan, People's Republic of China

${ }^{2}$ Department of Nuclear Medicine, The First Affiliated Hospital of Sun Yat-Sen University, Guangzhou, People's Republic of China detection of some tumors [5], and the high accumulation in the brain limiting the detection of brain metastases [6, 7]. Given the limitations of ${ }^{18}$ F-FDG PET imaging, the novel imaging agents with greater tumor specificity are required.

Some radiolabeled short carboxylic acids have been investigated for tumor imaging. Radiolabeled acetate (such as ${ }^{11} \mathrm{C}$-acetate) has been used for many years as a probe for measuring myocardial oxidative metabolism and tumor imaging [8-10], but the short half-life of ${ }^{11} \mathrm{C}$ (20.4 min) limited its widespread applications. ${ }^{18} \mathrm{~F}$-fluoroacetate $\left({ }^{18} \mathrm{~F}\right.$-FAC) has been developed as a mimic of ${ }^{11} \mathrm{C}$-acetate for imaging prostate cancer with higher tumor-to-background ratios than ${ }^{11} \mathrm{C}$-acetate [11]. $2{ }^{18}{ }^{18}$-fluoropropionic acid $\left({ }^{18} \mathrm{~F}\right.$-FPA) was another important mimic of ${ }^{11} \mathrm{C}$-acetate, which could delineate 
both androgen-dependent and androgen-independent prostate xenografts with high tumor-to-background ratios [12]. There was less report about ${ }^{18} \mathrm{~F}$-FAC and ${ }^{18} \mathrm{~F}$-FPA in inflammation imaging [13]. $4{ }^{-18} \mathrm{~F}$-fluorobenzoic acid $\left({ }^{18} \mathrm{~F}-\mathrm{FBA}\right)$ was initially developed as a fluorine-18-labeled reagent for coupling with small peptides from solid phase synthesis [14]. To the best of our knowledge, no studies about ${ }^{18} \mathrm{~F}-\mathrm{FBA}$ as a probe in PET imaging have been reported. Therefore, the main purpose of this study was to investigate the biodistribution and PET imaging of these three ${ }^{18} \mathrm{~F}$-labeled short carboxylic acids $\left({ }^{18} \mathrm{~F}-\mathrm{FAC},{ }^{18} \mathrm{~F}-\mathrm{FPA}\right.$ and $\left.{ }^{18} \mathrm{~F}-\mathrm{FBA}\right)$ and to evaluate their feasibility for differentiating between tumor and inflammation in model mice in comparison with ${ }^{18}$ F-FDG.

\section{Methods}

\section{Radiopharmaceuticals}

Automated synthesis of ${ }^{18} \mathrm{~F}$-FDG was performed on an automatic synthesizer (IBA, Belgium). ${ }^{18}$ F-FAC was produced by radiofluorination of benzyl bromoacetate and followed by deprotection using on-column basic hydrolysis according to the method described by Tang et al. [15]. ${ }^{18} \mathrm{~F}$-FPA was prepared according to our previously reported method including nucleophilic fluorination of the precursor methyl-2-bromopropionate and deprotection using on-column basic hydrolysis protocols [16]. ${ }^{18} \mathrm{~F}$-FBA was produced via two-step one-pot procedure consisting of radiofluorination of ethyl-4-(trimethylammoniumtriflate) benzoate and basic hydrolysis described by Marik and Sutcliffe [17].

\section{Animal models}

The animal experiments were approved by the Committee on Animal and Human Research at the First Affiliated Hospital, Sun Yat-Sen University. And a completed ARRIVE guidelines checklist for animal experiments is included in Supplementary Material. Female Kunming mice (20-25 g body weight) were obtained from Laboratory Animal Center of Sun Yat-Sen University. Tumor-bearing mice model and inflammation mice model were prepared in different mice as two separate models. S-180 fibrosarcoma cells were cultured in $\alpha$-minimum essential medium (MEM, containing $10 \%$ fetal bovine serum, $100 \mathrm{U} / \mathrm{mL}$ penicillin and $100 \mu \mathrm{g} / \mathrm{mL}$ streptomycin) at $37^{\circ} \mathrm{C}$ in a humidified atmosphere with $5 \% \mathrm{CO}_{2}$. Thirty mice were subcutaneously injected with S-180 fibrosarcoma cells $\left(6 \times 10^{6}\right.$ cells per mouse) into the right shoulder blade. The mass of the tumors grew to $8-10 \mathrm{~mm}$ within two weeks for the experiments.

Sterile inflammation was induced by injecting turpentine oil, which would give rise to chronic inflammation with fibroblasts, vascular proliferation and macrophage infiltration [18]. Turpentine oil $(0.2 \mathrm{~mL}$ per mouse) were intramuscularly injected into the right thigh muscle of mice $(n=30)$. Initial assessment of lesions was determined by visual examination and palpation, and lesions were allowed to grow for 3 days for the experiments.

\section{Biodistributions of ${ }^{18} \mathrm{~F}-\mathrm{FAC},{ }^{18} \mathrm{~F}-\mathrm{FPA}$ and ${ }^{18} \mathrm{~F}-\mathrm{FBA}$ in normal mice}

For the biodistribution study, the healthy Kunming mice were intravenously injected with $3.7 \mathrm{MBq}$ of ${ }^{18} \mathrm{~F}$-FAC, ${ }^{18} \mathrm{~F}$ FPA and ${ }^{18}$ F-FBA. Following the injection, animals were sacrificed at $5 \mathrm{~min}, 30 \mathrm{~min}, 60 \mathrm{~min}$ and $90 \mathrm{~min}(n=4$ each point). Blood was collected from retro-orbital bleeding, and the other normal tissues of interest, including the heart, brain, liver, kidney, pancreas, intestine, stomach, lung, muscle and bone in normal mice, were rapidly dissected and weighed. The radioactivity was counted with an auto-gamma counter. All measurements were background-subtracted and decay-corrected to the time of injection, then averaged together. Tissue radioactivity was expressed as percentage of injected dose per gram of tissue $(\% \mathrm{ID} / \mathrm{g})$.

\section{PET imaging with ${ }^{18} \mathrm{~F}$-FAC, ${ }^{18} \mathrm{~F}$-FPA, ${ }^{18} \mathrm{~F}$-FBA and ${ }^{18} \mathrm{~F}$-FDG}

PET images were obtained using an Advanced Scanner (GEMINI GXL-16, PHILIPS, Netherlands) in three-dimensional acquisition mode. The experimental animals were deeply anesthetized by intraperitoneal injection of $5 \%$ chloral hydrate $(10 \mathrm{~mL} / \mathrm{kg})$ before imaging and remained anesthetized through the study. PET scanning was performed on the 3 days after turpentine oil injection and 10 days after tumor implantation. Ten-minute static PET/CT scans were performed at $30 \mathrm{~min}, 60 \mathrm{~min}, 90 \mathrm{~min}$ and $120 \mathrm{~min}$ after intravenous (i.v.) administration of $3.7 \mathrm{MBq}$ of ${ }^{18} \mathrm{~F}$-labeled radiopharmaceuticals described above. PET images were reconstructed from the Line of Response (LOR) RAMLA algorithm with low-dose CT images for attenuation correction and localization of the lesion site, resulting in three-dimensional images consisting of $128 \times 128 \times 90$ voxels of $2.0 \times 2.0 \times 2.0 \mathrm{~mm}^{3}$. The regions of interest were placed on each tumor, inflammatory lesion and the region of left thigh muscle. After PET imaging, the animals were sacrificed, some interested tissues (blood, tumors, inflammation region of the right thigh muscle and normal muscle) were excised and weighted, and the radioactivities of these tissues were measured with the gamma counter. The selectivity index (SI) of radiotracers was the tumorto-inflammation ratio corrected for the background activity of blood or muscle according to the following formula: 


$$
\mathrm{SI}=\frac{[\text { Tumor uptake-Blood or Muscle uptake }]}{[\text { Inflammation uptake-Blood or Muscle uptake }]}
$$

\section{Histopathology}

The excised tumors, inflammation region of the thigh muscle and normal thigh muscle were fixed in formalin and embedded in paraffin. Five micron sections of each tissue were stained with hematoxylin and eosin, and examined for tumor and inflammatory region.

\section{Statistical analysis}

All reported values were expressed as mean \pm standard error of the mean. Differences among the various groups $\left({ }^{18} \mathrm{~F}\right.$-FDG, ${ }^{18} \mathrm{~F}$-FAC, ${ }^{18} \mathrm{~F}$-FPA and ${ }^{18} \mathrm{~F}$-FBA tissues uptake after PET imaging) were tested for statistical significance using the Student's $t$ test (or Wilcoxon signed rank test when the data dose not follow a normal distribution.), respectively. And the differences were considered significant at the $95 \%$ confidence level $(p<0.05)$.

\section{Results}

\section{Radiosynthesis}

Starting from benzyl bromoacetate and methyl-2-bromopropionate, the automated synthesis of ${ }^{18} \mathrm{~F}$-FAC and ${ }^{18} \mathrm{~F}$-FPA were performed in approximately $36 \mathrm{~min}$. And the uncorrected radiochemical yields were $55 \pm 5 \%$ and $46 \pm 7 \%(n=5)$ at end of synthesis for ${ }^{18} \mathrm{~F}$-FAC and ${ }^{18} \mathrm{~F}$ FPA, respectively. Using one-pot procedure and purification by SEP-PAK cartridges, the radiochemical yield of ${ }^{18} \mathrm{~F}$-FBA was $32 \pm 3 \%$ at end of synthesis ( $n=5$, decay uncorrected) within $50 \mathrm{~min}$. The specific activity of ${ }^{18} \mathrm{~F}$-FAC, ${ }^{18} \mathrm{~F}$-FPA and ${ }^{18} \mathrm{~F}$-FBA were $>37 \mathrm{GBq} / \mu$ mol with over than $95 \%$ radiochemical purity.

\section{Biodistributions of ${ }^{18} \mathrm{~F}-\mathrm{FAC},{ }^{18} \mathrm{~F}-\mathrm{FPA}$ and ${ }^{18} \mathrm{~F}$-FBA in normal mice}

Biodistributions of ${ }^{18} \mathrm{~F}$-FAC, ${ }^{18} \mathrm{~F}$-FPA and ${ }^{18} \mathrm{~F}$-FBA at different time phases in normal mice are shown in Fig. 1. For ${ }^{18}$ F-FAC (Fig. 1a), the elimination of radioactivity from blood was relatively slow within $60 \mathrm{~min}(6.64 \pm$ $1.40 \% \mathrm{ID} / \mathrm{g}$ at $5 \mathrm{~min}$ vs. $6.92 \pm 2.27 \% \mathrm{ID} / \mathrm{g}$ at $60 \mathrm{~min}$ postinjection, $p>0.05)$. In addition, the radioactivity accumulation in liver, lung, heart, muscle and pancreas showed a similar profile of radioactivity clearance as that in blood within $60 \mathrm{~min}$. But a higher radioactivity uptake in bone was found at $60 \mathrm{~min}$ postinjection $(6.68 \pm 0.43 \% \mathrm{ID} / \mathrm{g})$. For ${ }^{18} \mathrm{~F}$-FPA (Fig. 1b), the uptake of this tracer in most investigated organs remained constant throughout the experiment time of the study, and the distribution profile of ${ }^{18} \mathrm{~F}$-FPA in most tissues was similar to that of ${ }^{18} \mathrm{~F}$-FAC. However, the lower uptake of ${ }^{18} \mathrm{~F}$-FPA in bone was observed with the constant radioactivity accumulation over the whole time of study $(3.91 \pm 0.57 \% \mathrm{ID} / \mathrm{g}$ at $5 \mathrm{~min}$ vs. $3.02 \pm 0.07$ $\% \mathrm{ID} / \mathrm{g}$ at $90 \mathrm{~min}, p>0.05)$. For ${ }^{18} \mathrm{~F}-\mathrm{FBA}$, the most tissue uptakes at $60 \mathrm{~min}$ postinjection were lower than those of ${ }^{18} \mathrm{~F}-\mathrm{FAC}$ and ${ }^{18} \mathrm{~F}-\mathrm{FPA}$ (Fig. 1c), and the radioactivity clearance of ${ }^{18} \mathrm{~F}$-FBA from most tissues was very fast within the experiment time, especially for blood and kidneys (Blood: $3.63 \pm 1.77 \% \mathrm{ID} / \mathrm{g}$ at $5 \mathrm{~min}$ vs. $0.14 \pm 0.08 \% \mathrm{ID} / \mathrm{g}$ at $60 \mathrm{~min}, p<0.05$; Kidneys: $21.69 \pm 11.3 \% \mathrm{ID} / \mathrm{g}$ at $5 \mathrm{~min}$ vs. $0.34 \pm 0.18 \% \mathrm{ID} / \mathrm{g}$ at 60 min, $p<0.05$ ).

\section{PET imaging with ${ }^{18} \mathrm{~F}$-FDG, ${ }^{18} \mathrm{~F}$-FAC, ${ }^{18} \mathrm{~F}$-FPA and ${ }^{18} \mathrm{~F}$-FBA in model mice}

PET images of ${ }^{18} \mathrm{~F}$-FDG, ${ }^{18} \mathrm{~F}$-FAC, ${ }^{18} \mathrm{~F}$-FPA and ${ }^{18} \mathrm{~F}$-FBA obtained in tumor-bearing mice and inflammation mice are shown in Fig. 2. In the PET-CT images of tumorbearing mice, the radioactivity of ${ }^{18} \mathrm{~F}-\mathrm{FDG},{ }^{18} \mathrm{~F}$-FAC and ${ }^{18} \mathrm{~F}$-FPA is clearly localized in S-180 tumor on the right shoulder blade. In the PET-CT images of inflammatory mice, the highest uptake of ${ }^{18} \mathrm{~F}$-FDG in the inflammatory tissue and the moderate uptake of ${ }^{18} \mathrm{~F}$-FAC and ${ }^{18} \mathrm{~F}$-FPA were observed. For ${ }^{18} \mathrm{~F}$-FBA, the uptake in tumor revealed that ${ }^{18} \mathrm{~F}$-FBA accumulation was significantly lower than those of ${ }^{18} \mathrm{~F}$-FAC and ${ }^{18} \mathrm{~F}$-FPA. However, there is no significant ${ }^{18} \mathrm{~F}$-FBA uptake in inflammation lesions.

After PET imaging, the accumulations of radioactivity in blood, brain, liver, muscle, tumor and inflammatory lesions derived from the excised tissues, which were acquired at $60 \mathrm{~min}$ postinjection of tracers, are shown in Table 1.

The comparative orders of tumor-to-muscle $(\mathrm{Tu} / \mathrm{Mu})$ ratios were ${ }^{18} \mathrm{~F}$-FDG $\quad(6.30 \pm 0.69)>{ }^{18} \mathrm{~F}$-FBA $\quad(2.76 \pm$ $0.25)>{ }^{18}$ F-FPA $(1.80 \pm 0.19)>{ }^{18}$ F-FAC $(1.70 \pm 0.16)$. And the highest inflammation-to-muscle $(\mathrm{Inf} / \mathrm{Mu})$ ratio was $3.87 \pm 0.61$ for ${ }^{18} \mathrm{~F}-\mathrm{FDG}$, and other ratios of Inf/Mu basically were close for ${ }^{18} \mathrm{~F}$-FAC $(1.42 \pm 0.13),{ }^{18} \mathrm{~F}$-FBA $(1.40 \pm 0.13)$ and ${ }^{18} \mathrm{~F}-\mathrm{FPA}(1.38 \pm 0.13)$. For ${ }^{18} \mathrm{~F}$-FAC, the high radioactivity accumulation in muscle made it difficult to differentiate between tumor and inflammation $(\mathrm{Tu} / \mathrm{Mu}$ vs. $\mathrm{Inf} / \mathrm{Mu}: 1.70 \pm 0.16$ vs. $1.42 \pm 0.13, \mathrm{p}>0.05)$. Although the ${ }^{18} \mathrm{~F}$-FPA had the similar tumor-toinflammation ratio to that of ${ }^{18} \mathrm{~F}-\mathrm{FAC}$, the selectivity indices (SI) (Tu/Inf ratios corrected with muscle and blood uptake) of ${ }^{18} \mathrm{~F}$-FPA $(3.52 \pm 0.13$ and $8.00 \pm 1.37)$ were significantly higher than those of ${ }^{18} \mathrm{~F}$-FAC $(1.74 \pm$ 0.16 and $1.59 \pm 0.12$ ). For ${ }^{18} \mathrm{~F}-\mathrm{FBA}$, significant lower radioactivity accumulations were observed in tumor and inflammatory lesion, but the Tumor-to-inflammation $(\mathrm{Tu} / \mathrm{Inf})$ ratio of ${ }^{18} \mathrm{~F}-\mathrm{FBA}$ was the highest $(1.98 \pm 0.15)$ among these experimental PET tracers due to the lower inflammation uptake. Being corrected with the background uptake of muscle, ${ }^{18} \mathrm{~F}$-FBA has a supreme selectivity index (SI) (Muscle corrected, $3.72 \pm 0.06$ ) due to its 


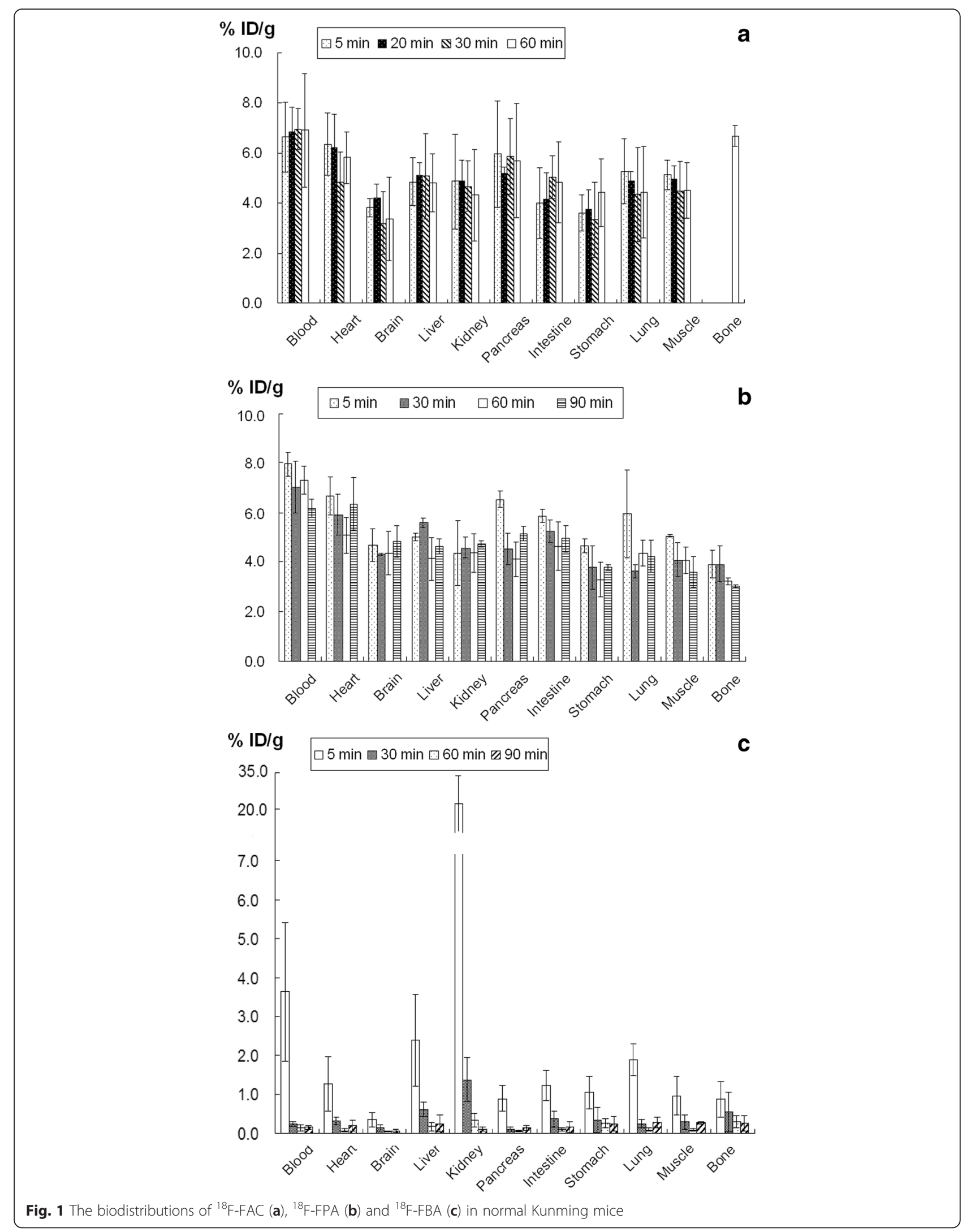




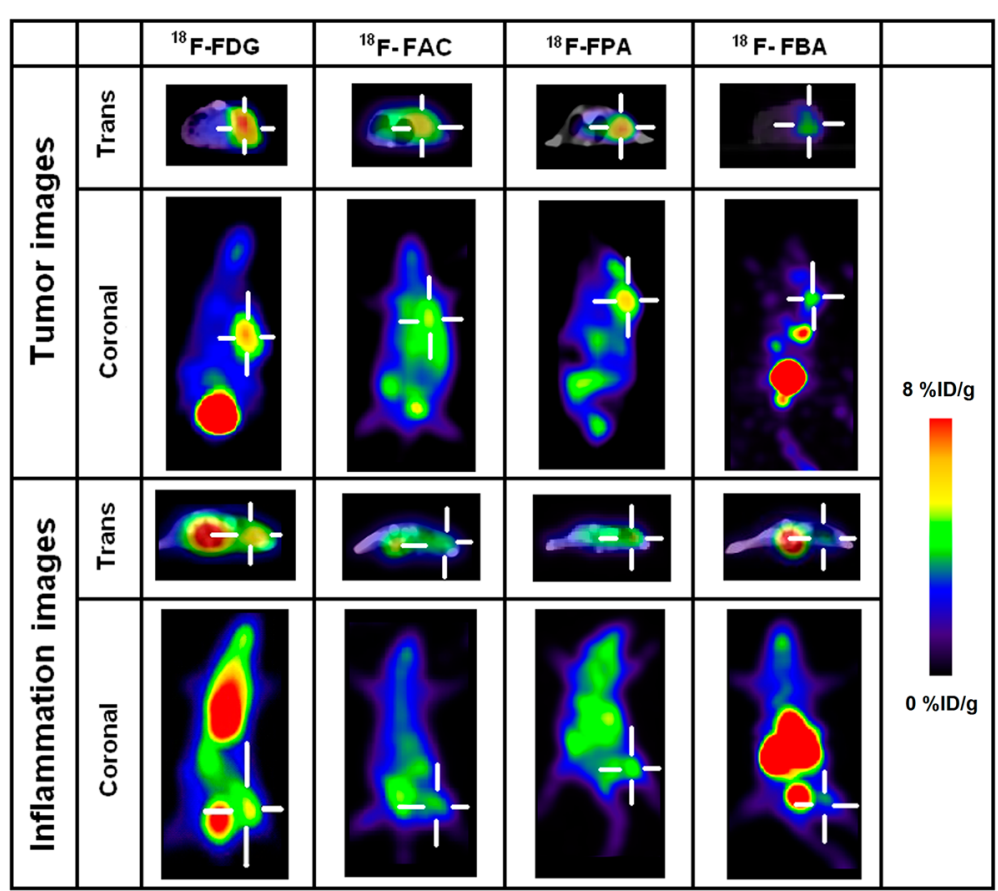

Fig. 2 PET images of S180 fibrosarcoma-bearing mice model (the up two rows) and sterile inflammation mice model (the below two rows) with ${ }^{18} \mathrm{~F}-\mathrm{FDG},{ }^{18} \mathrm{~F}-\mathrm{FAC},{ }^{18} \mathrm{~F}-\mathrm{FPA}$ and ${ }^{18} \mathrm{~F}-\mathrm{FBA}$ at $60 \mathrm{~min}$ postinjection. Four short white lines indicate the location of tumor or inflammatory lesion areas, respectively

comparatively low radioactivity accumulation in the inflammatory lesion. Our results indicated that ${ }^{18} \mathrm{~F}$-FBA was specifically retained in S180 fibrosarcoma lesions.

\section{Histopathologic findings of tumors and inflammation}

Histological examination revealed malignant mesenchymal tumor in a specimen of the excised S-180 tumors. S-180 tumor cells with pleomorphic, hyperchromatic nuclei were arranged in tumor mass and many mitoses were found (Fig. 3a). As shown in Fig. 3b, histological examination demonstrated inflammatory reaction in a specimen of the turpentine oil-injected muscle, and massive infiltration of neutrophils was seen in and between muscle fibers.

Table 1 Accumulation comparison of ${ }^{18} \mathrm{~F}-\mathrm{FAC},{ }^{18} \mathrm{~F}-\mathrm{FPA},{ }^{18} \mathrm{~F}-\mathrm{FBA}$ and ${ }^{18} \mathrm{~F}-\mathrm{FDG}$ (3.7 MBq in saline) in model mice $(n=3)$

\begin{tabular}{|c|c|c|c|c|}
\hline & ${ }^{18} \mathrm{~F}-\mathrm{FDG}$ & ${ }^{18} \mathrm{~F}-\mathrm{FAC}$ & ${ }^{18} \mathrm{~F}-\mathrm{FPA}$ & ${ }^{18} \mathrm{~F}-\mathrm{FBA}$ \\
\hline$\overline{\text { Blood }^{a}}$ & $0.72 \pm 0.18$ & $3.36 \pm 1.66$ & $4.35 \pm 1.09$ & $0.05 \pm 0.01$ \\
\hline Muscle $^{a}$ & $1.06 \pm 0.47$ & $3.73 \pm 0.53$ & $3.87 \pm 0.42$ & $0.22 \pm 0.02$ \\
\hline Tumor $^{a}$ & $6.67 \pm 1.13$ & $6.12 \pm 1.76$ & $6.51 \pm 1.28$ & $0.63 \pm 0.10$ \\
\hline Inflammation ${ }^{a}$ & $4.11 \pm 1.96$ & $5.10 \pm 0.33$ & $4.62 \pm 0.33$ & $0.31 \pm 0.04$ \\
\hline Tumor-to-Blood ${ }^{b}$ & $1.68 \pm 0.26$ & $1.82 \pm 0.45$ & $1.50 \pm 0.36$ & $12.60 \pm 2.12$ \\
\hline Inflammation-to-Blood & $1.03 \pm 0.14$ & $1.52 \pm 0.21$ & $1.06 \pm 0.26$ & $6.20 \pm 1.06$ \\
\hline Tumor-to-Muscle & $6.30 \pm 0.69$ & $1.70 \pm 0.16$ & $1.80 \pm 0.19$ & $2.76 \pm 0.25$ \\
\hline Inflammation-to-Muscle & $3.87 \pm 0.61$ & $1.42 \pm 0.13$ & $1.38 \pm 0.13$ & $1.40 \pm 0.13$ \\
\hline Tumor-to-Inflammation & $1.63 \pm 0.28$ & $1.20 \pm 0.38$ & $1.41 \pm 0.33$ & $1.98 \pm 0.15^{*}$ \\
\hline SI (Blood) ${ }^{c}$ & $1.76 \pm 0.23$ & $1.59 \pm 0.12$ & $8.00 \pm 1.37^{*}$ & $2.23 \pm 0.34$ \\
\hline SI (Muscle) $)^{d}$ & $1.84 \pm 0.17$ & $1.74 \pm 0.16$ & $3.52 \pm 0.13^{*}$ & $3.72 \pm 0.06^{*}$ \\
\hline
\end{tabular}

${ }^{a}$ Values were presented as $\% \mathrm{ID} / \mathrm{g}$ (mean $\left.\pm \mathrm{SD}\right)$

${ }^{\mathrm{b}}$ Defined as (Tumor uptake)/(Blood uptake)

'Defined as (Tumor uptake - Blood uptake)/ (Inflammation uptake - Blood uptake), that is, Tu/Inf ratio corrected for blood background activity

${ }^{\mathrm{d}} \mathrm{Tu} / \mathrm{Inf}$ ratio corrected for Muscle background activity

${ }^{*} p<0.05$, vs. the ratios for ${ }^{18} \mathrm{~F}$-FDG 


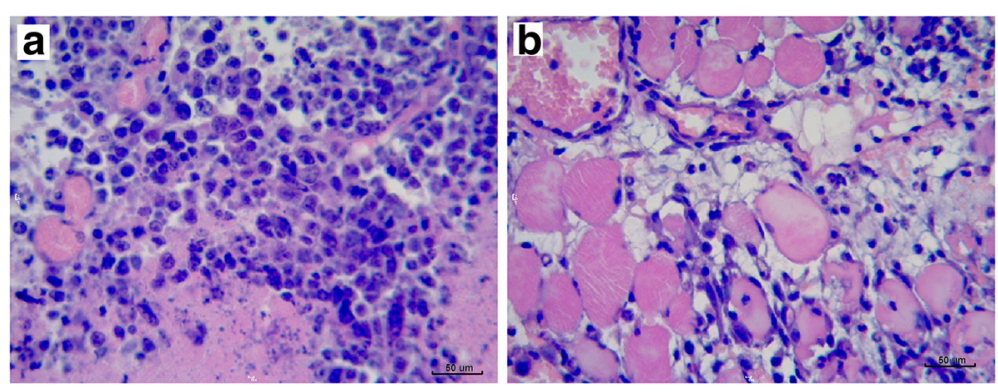

Fig. 3 Microscopic histological examination of a specimen excised from tumor and inflammation in mice. A specimen of mice tumor (a), 10 days after inoculation of S-180 cells and the mice inflammatory muscle (b), $72 \mathrm{~h}$ after injection of turpentine oil (all specimens were stained by hematoxylin and eosin and magnified by $\times 400$ )

\section{Discussion}

In the view of the positive accumulation of ${ }^{18}$ F-FDG in both tumor and inflammatory cells, the false-positive findings are always accompanied with uptake of ${ }^{18} \mathrm{~F}$ FDG in the inflammatory lesions, such as the abscess or granulation tissues surrounding the abscess. Hence, many radiotracers have been developed to use in differentiating tumor from inflammatory lesions [19, 20]. Radiolabeled short carboxylic acids would be an additional tool in characterizing the tumor by measuring the lipid metabolism. Tumor uptake of radiolabeled acetate not only reflects the expression of cytosolic acetyl-coenzyme A (CoA) synthetase [8], but also the fatty acid synthase [21]. The fatty acid synthase is overexpressed in various cancers and could catalyze the de novo synthesis of fatty acids from acetyl-CoA $[22,23]$. In this study, the feasibility of differentiation between tumor and inflammation in vivo with positron emitterlabeled short chain alkyl and aryl carboxylic acids was investigated and compared with ${ }^{18} \mathrm{~F}$-FDG.

In the biodistribution studies, the two short alkyl carboxylic acids $\left({ }^{18} \mathrm{~F}\right.$-FAC and ${ }^{18} \mathrm{~F}$-FPA) showed the similar characteristic of pharmacokinetics. The most tissues performed both higher radioactivity accumulation and slower clearance for ${ }^{18} \mathrm{~F}$-FAC and ${ }^{18} \mathrm{~F}$-FPA than those of ${ }^{18} \mathrm{~F}$-FBA. The main reason for the slow clearance of ${ }^{18} \mathrm{~F}$ FAC from those tissues could be attributed to the lack of oxidative metabolism in tissues and the slow transformation of ${ }^{18} \mathrm{~F}$-FAC to $2-{ }^{18} \mathrm{~F}$-fluoroacetyl-CoA [24], as well as the fluorocitric acid (in vivo) conversed from $2-{ }^{18} \mathrm{~F}$ fluoroacetyl-CoA could inhibit the aconitase causing the inhibition of the tricarboxylic acid cycle [24, 25]. Several studies have reported the utilization of propionate as a favoured energy substrate by heart and tumor cells [25-29]. And the metabolism of propionic acid begins with its conversion to propionyl-CoA catalyzed by mitochondrial propionyl-CoA synthetases [30,31], as the first common step in the metabolism of fatty acids. Therefore, ${ }^{18} \mathrm{~F}$-FPA could have a similar metabolic mechanism to ${ }^{18} \mathrm{~F}$-FAC. Unlike the significant defluorination of ${ }^{18} \mathrm{~F}$-FAC (Fig. 1a),
${ }^{18} \mathrm{~F}$-FPA within $90 \mathrm{~min}$ postinjection appeared to show no evidence of defluorination (Fig. 1b), which was consistent with previous studies [12]. In contrast, ${ }^{18}$ F-FBA showed a faster radioactivity clearance from most tissues within 60 min postinjection. Meanwhile, most tissues had a lower radioactivity uptake of ${ }^{18} \mathrm{~F}$-FBA after 5 min postinjection than those of ${ }^{18} \mathrm{~F}$-FAC and ${ }^{18} \mathrm{~F}$-FPA, so that ${ }^{18} \mathrm{~F}$-FBA performed the low bioavailability and the primarily excretion from kidney, which would result in a massively radioactivity accumulation in bladder (Fig. 2).

In this study, the S-180 fibrosarcoma is a malignant mesenchymal tumor derived from fibrous connective tissue and characterized by the presence of immature proliferating fibroblasts or undifferentiated anaplastic spindle cells in a storiform pattern. And the animal model of inflammation in the current study is chronic inflammation characterized by fibroblast proliferation and neovascularization with mononuclear cell infiltration (macrophages, lymphocytes and plasma cells) [18]. Therefore, we investigated the fibroblasts cells uptake for different probes in these models both with fibroblast proliferation. Our previous reports had shown that ${ }^{18} \mathrm{~F}$-FDG/PET exhibited high accumulations both in S-180 fibrosarcoma tumor and inflammation lesions [31, 32]. The ${ }^{18} \mathrm{~F}$-FDG uptake in tumor and inflammatory were 6.30-fold and 3.87-fold higher than that in healthy muscle, respectively (Table 1 ). All these results proved that ${ }^{18} \mathrm{~F}$-FDG could not effectively achieve the differentiation between tumor and inflammation [33]. Both ${ }^{18} \mathrm{~F}$-FAC and ${ }^{18} \mathrm{~F}$-FPA also successfully delineated tumor xenografts and inflammation lesions in model mice. For ${ }^{18} \mathrm{~F}$-FPA, the ratio of tumorto-inflammation was lower than that of ${ }^{18} \mathrm{~F}$-FDG (Table 1), but the higher selectivity indices of tumor-toinflammation (muscle or blood corrected ratios of tumor-to-inflammation, $3.52 \pm 0.13$ or $8.00 \pm 1.37$ ) were observed. The significant uptake of ${ }^{18} \mathrm{~F}$-FAC and ${ }^{18} \mathrm{~F}$ FPA in the inflammatory lesions might be attributed to the high expression of the acetyl- or propionyl-CoA synthetases and fatty acid synthnase in these tissues [34-36]. In addition, the higher uptake of ${ }^{18} \mathrm{~F}-\mathrm{FAC}$ and 
${ }^{18} \mathrm{~F}$-FPA were observed in the lower part of the gut, which was a result of the re-absorption of small carboxylic acids occurrence [37].

For ${ }^{18} \mathrm{~F}-\mathrm{FBA}$, the biodistribution studies demonstrated that ${ }^{18} \mathrm{~F}$-FBA had an advantage of rapid clearance in the most tissues. The differences of biodistribution between ${ }^{18} \mathrm{~F}$-FBA and ${ }^{18} \mathrm{~F}$-FAC (or ${ }^{18} \mathrm{~F}$-FPA) could be attributed to the different metabolic pathway, and ${ }^{18} \mathrm{~F}$-FBA was converted into $p-{ }^{18} \mathrm{~F}$-fluorohippuric acid derivatives via a glycine-conjugation pathway in the liver and eliminated through the kidneys [38-40]. Meanwhile, ${ }^{18}$ F-FBA PET imaging showed the clear contrast between tumor and inflammation lesion with the highest ratios of tumor-toinflammation as $1.98 \pm 0.15$. Although both the fast clearance and low uptake in the most tissues rendered the high selectivity index of ${ }^{18} \mathrm{~F}$-FBA (Muscle or Blood corrected ratios of tumor-to-inflammation, $3.72 \pm 0.06$ or $2.23 \pm 0.34$ ), the low radioactivity accumulation in tumor and inflammation would be adverse for the delimitation of the interested tissues in PET imaging. Due to the low uptake of ${ }^{18} \mathrm{~F}$-FBA in tumor, some new strategies should be attempted to modify the profiles of ${ }^{18} \mathrm{~F}$-FBA to improve its pharmacokinetics. Recently, it was reported that the new benzoic acid derivatives could be conjugated with amino acids to provide new potential PET tracers for tumor detection [41]. However, all these works needed to be further studied.

\section{Conclusion}

In this study, the ex vivo biodistribution and in vivo PET imaging results demonstrate that ${ }^{18} \mathrm{~F}$-FBA seems to be a potential PET tracer to detect tumor and to differentiate tumor from inflammation in comparison with ${ }^{18} \mathrm{~F}$-FDG and ${ }^{18} \mathrm{~F}$-FAC (or ${ }^{18} \mathrm{~F}$-FPA). And the structure modification of ${ }^{18} \mathrm{~F}$-FBA would be performed to improve the profiles of biodistribution in the further studies.

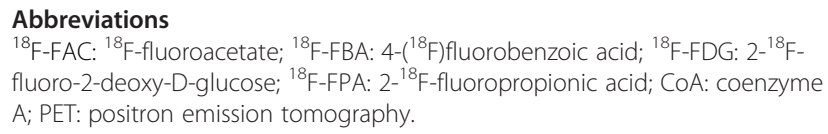

\section{Competing interests}

The authors declare that they have no competing interests.

\section{Authors' contributions}

The following authors participated in the design of the research: HLW and GHT. The following authors participated in the animal study: HLW, KZH, TTH and $X \mathrm{~L}$. The following authors participated in reading of the PET images: HLW, GHT, ZFW and SJL. The following authors participated in the analysis and interpretation of the data: GHT and SJL. All authors have participated in the drafting and revision of the manuscript and have approved it.

\section{Acknowledgements}

This work was partly supported by the National Natural Science Foundation (No. 81471695, 81371584, 30970856 and 81571716), The Doctoral Starting up Foundation of Shanxi Medical University (No. 03201316), Scientific and

Technologial Innovation Programs of Higher Education Institutions in Shanxi (No. 2014134), Science and Technology Planning Project of Guangzhou (2011 J5200025 and 2012B031800082).
Received: 6 October 2015 Accepted: 7 January 2016

Published online: 12 January 2016

\section{References}

1. Macheda ML, Rogers S, Best JD. Molecular and cellular regulation of glucose transporter (GLUT) proteins in cancer. J Cell Physiol. 2005;202:654-62.

2. Smith TA. Mammalian hexokinases and their abnormal expression in cancer. Br J Biomed Sci. 2000;57:170-8.

3. Cook GJ. Pitfalls in PET/CT interpretation. Q J Nucl Med Mol Imaging. 2007; 51:235-43.

4. Strauss LG. Fluorine-18 deoxyglucose and false-positive results: a major problem in the diagnostics of oncological patients. Eur J Nucl Med. 1996;23: 1409-15.

5. Oyama N, Akino H, Suzuki Y, Kanamaru H, Ishida H, Tanase K, et al. FDG PET for evaluating the change of glucose metabolism in prostate cancer after androgen ablation. Nucl Med Commun. 2001;22:963-9.

6. Giovannini E, Lazzeri P, Milano A, Gaeta MC, Ciarmiello A. Clinical applications of choline PET/CT in brain tumors. Curr Pharm Des. 2015;21:121-7.

7. Olivero WC, Dulebohn SC, Lister JR. The use of PET in evaluating patients with primary brain tumours: is it useful? J Neurol Neurosurg Psychiatry. 1995;58:250-2.

8. Choi Y, Huang SC, Hawkins RA, Hoh CK, Krivokapich J, Buxton DB, et al. A refined method for quantification of myocardial oxygen consumption rate using mean transit time with carbon-11-acetate and dynamic PET. J Nucl Med. 1993;34:2038-43.

9. Shreve P, Chiao PC, Humes HD, Schwaiger M, Gross MD. Carbon-11-acetate PET imaging in renal disease. J Nucl Med. 1995;36:1595-601.

10. Ho CL, Yu SC, Yeung DW. 11C-acetate PET imaging in hepatocellular carcinoma and other liver masses. J Nucl Med. 2003;44:213-21.

11. Ponde DE, Dence CS, Oyama N, Kim J, Tai YC, Laforest R, et al. 18Ffluoroacetate: a potential acetate analog for prostate tumor imaging-in vivo evaluation of 18F-fluoroacetate versus 11C-acetate. J Nucl Med. 2007;48:420-8.

12. Pillarsetty N, Punzalan B, Larson SM. 2-18F-Fluoropropionic acid as a PET imaging agent for prostate cancer. J Nucl Med. 2009;50:1709-14.

13. Liu RS, Chou TK, Chang CH, Wu CY, Chang CW, Chang TJ, et al. Biodistribution, pharmacokinetics and PET imaging of 18F-FMISO, 18F-FDG and 18F-FAc in a sarcoma- and inflammation-bearing mouse model. Nucl Med Biol. 2009;36(3): 305-12.

14. Sutcliffe-Goulden JL, O'Doherty MJ, Bansal SS. Solid phase synthesis of [18F]labelled peptides for positron emission tomography. Bioorg Med Chem Lett. 2000;10:1501-3.

15. Tang XL, Tang GH, Wang MF, Li BY, Liang MQ, Wang QS. A simple and rapid automated radiosynthesis of [18F]fluoroacetate. J Label Compd Radiopharm. 2008;1:297-301.

16. Wang HL, Hu KZ, Tang GH, Huang TT, Liang X. Simple and efficient automated radiosynthesis of 2-18F-fluoropropionic acid using solid-phase extraction cartridges purification. J Label Compd Radiopharm. 2012;55:366-70.

17. Marik J, Sutcliffe JL. Fully automated preparation of n.c.a. 4[18F]fluorobenzoic acid and N-succinimidyl 4-[18F]fluorobenzoate using a Siemens/CTI chemistry process control unit (CPCU). Appl Radiat Isot. 2007; 65:199-203.

18. Yamada S, Kubota K, Kubota R, Ido T, Tamahashi N. High accumulation of fluorine-18-fluorodeoxyglucose in turpentine-induced inflammatory tissue. J Nucl Med. 1995;36:1301-6.

19. van Waarde A, Cobben DC, Suurmeijer AJ, Maas B, Vaalburg W, de Vries EF, et al. Selectivity of 18F-FLT and 18F-FDG for differentiating tumor from inflammation in a rodent model. J Nucl Med. 2004;45:695-700.

20. Chang $\mathrm{CH}$, Wang HE, Wu SY, Fan KH, Tsai TH, Lee TW, et al. Comparative evaluation of FET and FDG for differentiating lung carcinoma from inflammation in mice. Anticancer Res. 2006;26:917-25.

21. Kuhjda FP. Fatty acid synthase and cancer: new application of an old pathway. Cancer Res. 2006;66:5977-80.

22. Menendez JA, Lupu R. Fatty acid synthase and the lipogenic phenotype in cancer pathogenesis. Nat Rev Cancer. 2007;7:763-77.

23. Vavere AL, Kridel SJ, Wheeler FB, Lewis JS. 1-11C-acetate as a PET radiopharmaceutical for imaging fatty acid synthase expression in prostate cancer. J Nucl Med. 2008;49:327-34.

24. Lindhe O, Sun A, Ulin J, Rahman O, Langstrom B, Sorensen J. [(18)F]Fluoroacetate is not a functional analogue of [(11)Clacetate in normal physiology. Eur J Nucl Med Mol Imaging. 2009;36:1453-9. 
25. Fonnum F, Johnsen A, Hassel B. Use of fluorocitrate and fluoroacetate in the study of brain metabolism. Glia. 1997;21:106-13.

26. Goncharov NV, Jenkins RO, Radilov AS. Toxicology of fluoroacetate: a review, with possible directions for therapy research. J Appl Toxicol. 2006;26:148-61.

27. Kasumov T, Cendrowski AV, David F, Jobbins KA, Anderson VE, Brunengraber $\mathrm{H}$. Mass isotopomer study of anaplerosis from propionate in the perfused rat heart. Arch Biochem Biophys. 2007;463:110-7.

28. Malaisse WJ, Zhang TM, Verbruggen I, Willem R. Enzyme-to-enzyme channelling of Krebs cycle metabolic intermediates in Caco-2 cells exposed to [2-13c]propionate. Biochem J. 1996;317(Pt 3):861-3.

29. Wehrle JP, Ng CE, McGovern KA, Aiken NR, Shungu DC, Chance EM, et al. Metabolism of alternative substrates and the bioenergetic status of EMT6 tumor cell spheroids. NMR Biomed. 2000;13:349-60.

30. Ricks CA, Cook RM. Regulation of volatile fatty acid uptake by mitochondrial acyl CoA synthetases of bovine liver. J Dairy Sci. 1981;64:2324-35.

31. Huang $T$, Wang $H$, Tang $G$, Liang $X$, Nie $D$, Yi C, et al. A comparative uptake study of multiplexed PET tracers in mice with turpentine-induced inflammation. Molecules. 2012;17:13948-59.

32. Wang $H$, Tang $X$, Tang G, Huang $T$, Liang $X$, Hu K, et al. Noninvasive positron emission tomography imaging of cell death using a novel small-molecule probe, (18)F labeled bis(zinc(II)-dipicolylamine) complex. Apoptosis. 2013;18:1017-27.

33. Lee TS, Ahn SH, Moon BS, Chun KS, Kang JH, Cheon GJ, et al. Comparison of 18F-FDG, 18F-FET and 18F-FLT for differentiation between tumor and inflammation in rats. Nucl Med Biol. 2009;36:681-6.

34. Consolazio A, Alo PL, Rivera M, lacopini F, Paoluzi OA, Crispino P, et al. Overexpression of fatty acid synthase in ulcerative colitis. Am J Clin Pathol. 2006;126:113-8.

35. Ottey KA, Wood LC, Grunfeld C, Elias PM, Feingold KR. Cutaneous permeability barrier disruption increases fatty acid synthetic enzyme activity in the epidermis of hairless mice. J Invest Dermatol. 1995;104:401-4.

36. Wakamiya T, Suzuki SO, Hamasaki H, Honda H, Mizoguchi M, Yoshimoto K, et al. Elevated expression of fatty acid synthase and nuclear localization of carnitine palmitoyltransferase $1 \mathrm{C}$ are common among human gliomas. Neuropathology. 2014;34:465-74

37. Rombeau JL, Kripke SA. Metabolic and intestinal effects of short-chain fatty acids. JPEN J Parenter Enteral Nutr. 1990;14:181S-5.

38. Pathuri G, Agashe HB, Awasthi V, Gali H. Radiosynthesis and in vivo evaluation of a F-18-labeled pancreatic islet amyloid inhibitor. J Label Compd Radiopharm. 2009;53:186-91.

39. Pan $\mathrm{H}$, Zhou $\mathrm{H}$, Zeng $\mathrm{S}$, Xu X, An H, Jiang $\mathrm{H}$. Identification and simultaneous determination of p-FHA and p-FBA, two metabolites of anti-tumor agentFluorapacin in rat urine. J Chromatogr B Analyt Technol Biomed Life Sci. 2009:877:1553-60.

40. Awathi V, Pathuri G, Agashe HB, Gali H. Synthesis and in vivo evaluation of p-18F-Fluorohippurate as a new radiopharmaceutical for assessment of renal function by PET. J Nucl Med. 2011;52:147-53.

41. He $Y$, $X u$ JL, Liu H, Feng M, Wang $X$, Ding R, et al. Synthesis of 2-R1-2-(4-(2fluoroethoxy)benzamido)acetate as potential PET imaging agents. Med Chem Res. 2011:11:9577-85.

\section{Submit your next manuscript to BioMed Central and we will help you at every step:}

- We accept pre-submission inquiries

- Our selector tool helps you to find the most relevant journal

- We provide round the clock customer support

- Convenient online submission

- Thorough peer review

- Inclusion in PubMed and all major indexing services

- Maximum visibility for your research

Submit your manuscript at www.biomedcentral.com/submit

) Biomed Central 